\title{
Expression and clinical significance of the obesity-related gene TNFAIP9 in obese children
}

\author{
L.Y. Gui ${ }^{1}$, Y.L. Hu ${ }^{1}$, Z.L. Hou ${ }^{2}$ and P. Wang ${ }^{1}$ \\ ${ }^{1}$ Department of Pediatrics, Pediatrics, Women \& Infants Hospital of Zhengzhou, \\ Zhengzhou, China \\ ${ }^{2}$ Minimally Invasive Surgery, Henan Province Chest Hospital, Zhengzhou, China \\ Corresponding author: L.Y. Gui \\ E-mail: linyanguicn@163.com \\ Genet. Mol. Res. 15 (3): gmr.15037995 \\ Received November 5, 2015 \\ Accepted June 8, 2016 \\ Published August 18, 2016 \\ DOI http://dx.doi.org/10.4238/gmr.15037995 \\ Copyright $(2016$ The Authors. This is an open-access article distributed under the terms of \\ the Creative Commons Attribution ShareAlike (CC BY-SA) 4.0 License.
}

\begin{abstract}
To investigate the expression of tumor necrosis factoralpha inducible protein 9 (TNFAIP9) gene in obese children and its clinical significance, 36 simple obese children and 17 non-obese children were recruited as research subjects. The adipose tissue was obtained by abdominal operation. The expression of TNFAIP9 was detected using real-time fluorescence quantitative polymerase chain reaction and western blot. The relationship between the expression of TNFAIP9 and blood lipid, blood glucose, and obesity indexes was analyzed. The levels of TNFAIP9 mRNA and protein in obese children were significantly lower than those in the control group $(\mathrm{P}<0.05)$. The waist circumference (wc), body mass, body mass index (BMI), fat, total cholesterol (TC), triglyceride (TG), low-density lipoprotein cholesterol (LDL-C), insulin resistance index (HOMA-IR), and endothelin (ET) in obese children were significantly higher than those in the control group. The level of high-density lipoprotein cholesterol (HDL-C) was significantly lower than that in the control group $(\mathrm{P}<0.05)$. The level
\end{abstract}


of TNFAIP9 protein was negatively correlated with the wc, body mass, BMI, fat, TC, TG, LDL-C, HOMA-IR, and ET $(\mathrm{P}<0.05)$ and was positively correlated with the level of HDL-C $(\mathrm{P}<0.05)$. In conclusion, the expression of TNFAIP9 significantly decreased in the adipose tissue of obese children, and its levels are closely related to blood lipid level, insulin resistance, and obesity.

Key words: TNFAIP9; Obese children; Lipid; Insulin resistance

\section{INTRODUCTION}

Obesity is a chronic metabolic disease caused by many factors. It is characterized by an increase in adipocyte volume and number, resulting in an abnormal increase in body fat accounting for body weight and locally excessive deposition of fat (Schwingshackl and Hoffmann, 2013; Johnston et al., 2014). The fat distribution in simple obese patients is relatively uniform and is not accompanied by endocrine or metabolic disorders. Often, there is a family history of obesity (Chen, 2009). In recent years, the number of simple obese children is increasing worldwide. Simple obesity is the main risk factor for hypertension, atherosclerosis, coronary heart disease, and diabetes. It has become a serious disease that threatens child health (Ji et al., 2004). Therefore, the focus of the current study is the investigation of the pathogenesis of simple obesity in children. Recent studies have shown that the body of obese children is in a chronically low-grade state of inflammation. The concentrations of proinflammatory factors in peripheral blood, such as tumor necrosis factor-alpha (TNF- $\alpha$ ) and interleukin (IL)-6, were significantly increased (Bastard et al., 2006; Esser et al., 2014). TNF- $\alpha$ inducible protein (TNFAIP) is a family containing a variety of proteins that are closely related to many autoimmune diseases and tumors (Liu et al., 2010; Ando et al., 2013; Zhang et al., 2013). TNFAIP9 is a member of the tumor necrosis factor family of proteins and a current study suggested that it might be associated with obesity (Inoue et al., 2012). In this study, to investigate the pathogenesis of obesity, the relationship between TNFAIP9 and obesity was analyzed.

\section{MATERIAL AND METHODS}

\section{Clinical data}

Thirty-six obese children receiving treatment in our hospital from February 2013 to February 2015 were selected as the observation group. All patients' body mass index (BMI) was greater than the 95th percentile (P95) and the group included 20 males and 16 females, aged 7-14 years old. The average age was $10.12 \pm 3.02$ years. The obese children had no diabetes, malignant tumors, or other metabolic diseases. At the same time, 17 children with standard body weight receiving surgical abdominal operations were selected as the control group, and the group included 10 males and 7 females, aged 7-15 years old. The average age was $10.89 \pm 2.76$ years. The retroperitoneal adipose tissue of children in both groups was removed. This study was conducted in accordance with the declaration of Helsinki and with approval from the Ethics Committee of Pediatrics, Women \& Infants Hospital of Zhengzhou (China). Written informed consent was obtained from the parents of all subjects.

Genetics and Molecular Research 15 (3): gmr.15037995 


\section{Real-time quantitative polymerase chain reaction (PCR)}

Adipose tissue $(0.1 \mathrm{~g})$ was removed from each child in each group. The total RNA was extracted according to the manufacturer instructions for the RNA extraction kit (TaKaRa, Dalian, China). The precipitate was washed with cold $75 \%$ anhydrous ethanol twice and dissolved in RNA-free double distilled water. The sample concentration was determined. RNA was transcribed into cDNA as PCR template using the reverse transcription kit (TaKaRa). The primers were designed according to the TNFAIP9 and GAPDH mRNA sequences provided by GenBank. The primers for TNFAIP9 were: forward, 5'-CGAAACTTCCCTCTACCCG-3' and reverse, 5'-ACACAAACACCTGCCGACTT-3'. The primers for GAPDH were: forward, 5'-CCTTCCGTGTTCCTACCC-3' and reverse, 5'-CAACCTGGTCCTCAGTGTAG-3'. The primers were diluted to $10 \mu \mathrm{M}$, and their specificity and annealing temperature were optimized. The PCR system was prepared in a total reaction volume of $20 \mu \mathrm{L}$. PCR was conducted according to the following reaction conditions: pre-denaturation at $94^{\circ} \mathrm{C}$ for 2 min and 35 cycles of denaturation at $94^{\circ} \mathrm{C}$ for $30 \mathrm{~s}$, annealing at $60^{\circ} \mathrm{C}$ for $30 \mathrm{~s}$, and extension at $72^{\circ} \mathrm{C}$ for $30 \mathrm{~s}$. To determine the specificity of the product, the solubility curve was constructed. Finally, the data were read directly from the real-time fluorescence quantitative PCR instrument (Applied Biosystems, Foster City, CA, USA).

\section{Western blot analysis}

We removed a 1-g sample of adipose tissue from each child in each group, to which $500 \mu \mathrm{L}$ cell lysate was added and homogenized. A 1:9 volume of $100 \%$ TCA was added and the tube was carefully turned 10 times to mix evenly. The sample was placed in an ice bath for more than $0.5 \mathrm{~h}$ and centrifuged at 15,000 rpm for $20 \mathrm{~min}$. After this, a dark-brown precipitate was observed and the supernatant was discarded. The Eppendorf tube was upturned on absorbent paper and gently shaken to remove the residual liquid. The Eppendorf tube was upturned on the absorbent paper and incubated at $37^{\circ} \mathrm{C}$ for $20 \mathrm{~min}$ or until no obvious residual liquid was left at the bottom of the tube. The sample was centrifuged at 15,000 rpm for 10-20 $\mathrm{min}$. The residual liquid at the bottom of the tube was removed with a $20-\mu \mathrm{L}$ micropipette. Loading buffer $(20-50 \mu \mathrm{L})$ was added to each sample and heated at $95^{\circ} \mathrm{C}$ for $10 \mathrm{~min}$. After SDS-PAGE, the protein bands were transferred to PVDF film using a horizontal electrophoresis apparatus, blocked for 30 min with 5\% skim milk, and incubated with the primary antibody (Abcam, Cambridge, UK) overnight. On the next day, they were washed (for $5 \mathrm{~min}$ ) three times, incubated with the secondary antibody (Boster, Wuhan, China) for $1 \mathrm{~h}$, and washed with PBS (for $5 \mathrm{~min}$ ) three times. The chemiluminescence reagent was placed on the PVDF film for developing. GAPDH was used as the internal reference.

\section{Detection of blood lipid, fasting blood glucose and fasting insulin levels}

Fasting venous blood was drawn from patients in two groups in the morning and centrifuged at $4000 \mathrm{rpm}$ for $10 \mathrm{~min}$. The supernatant was kept. Total cholesterol (TC), triglycerides (TG), low-density lipoprotein cholesterol (LDL-C), and high-density lipoprotein cholesterol (HDL-C) were detected by the enzyme method. The kit was purchased from Dongou Biological Engineering Co., Ltd., Wenzhou, China. Fasting plasma glucose (FPG) and fasting plasma insulin (FINS) were determined by the glucose oxidase method and

Genetics and Molecular Research 15 (3): gmr.15037995 
radioimmunoassay. The kit was purchased from Hills Biological Co., Ltd., Shanghai, China. Insulin resistance index (HOMA-IR) was calculated according to the formula (FPG x FINS) / 22.5. Endothelin (ET) was measured by radioimmunoassay, and the kit was purchased from the East Asian Institute of the PLA General Hospital, Beijing, China. Body mass index (BMI) and waist circumference $(\mathrm{wc})$ of all the subjects were measured by a specially assigned person. BMI was measured when the patient was fasting and wearing underwear after urinary and bowel elimination. The wc was measured in a standing position and calculated by the circumference around the abdomen across the navel. The BMI was calculated according to the formula $\mathrm{BMI}=$ body mass $(\mathrm{kg}) /$ height $(\mathrm{m})^{2}(\mathrm{Fu}$ et al., 2014).

\section{Statistical analysis}

All data were analyzed by the SPSS 13.0 statistical software (SPSS Inc, Chicago, IL, USA). The measured data are reported as means \pm standard deviation. The measured data were compared using independent sample $t$-tests. $\mathrm{P}<0.05$ indicated that the difference was statistically significant.

\section{RESULTS}

\section{Comparison of TNFAIP9 mRNA levels in adipose tissue between two groups}

As shown in Figure 1, the amplification curve established by real-time fluorescent quantitative PCR reaction system was good in this study. The primer specificity was high without an impure peak. The quantitative analysis results showed that the level of TNFAIP9 mRNA in the control group was significantly higher than that in the obese group $(\mathrm{P}<0.05)$.

A

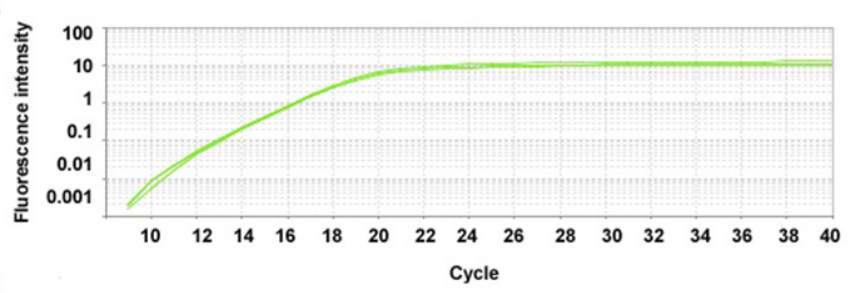

B

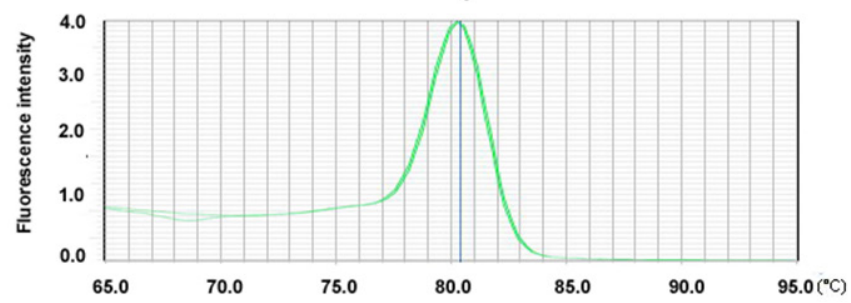

C

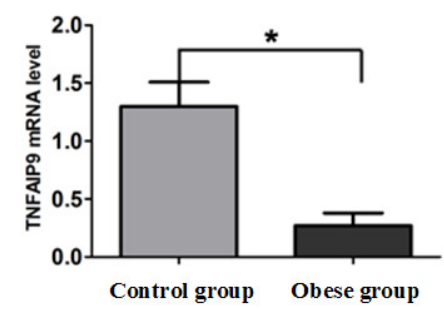

Figure 1. Comparison of TNFAIP9 mRNA levels in adipose tissue between the two groups. A. Amplification curve of real time PCR. B. Melting curve of real time PCR. C. Comparison of TNFAIP9 mRNA in adipose tissue of two groups. $* \mathrm{P}<0.05$.

Genetics and Molecular Research 15 (3): gmr.15037995 


\section{Comparison of TNFAIP9 protein levels in adipose tissue between two groups}

The levels of TNFAIP9 protein in adipose tissue between the two groups were further analyzed. Western blot analysis showed that the amount of TNFAIP9 protein in abdominal adipose tissue of children in the control group was significantly lesser than that in the obese group ( $\mathrm{P}<0.05$; Figure 2$)$.

A

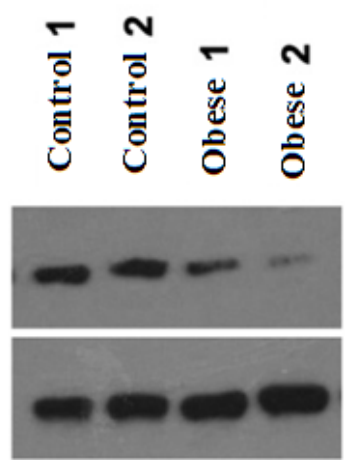

B

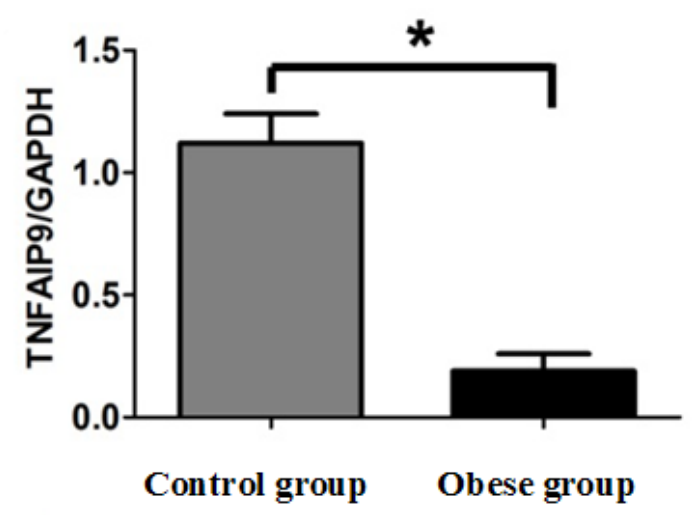

Figure 2. Comparison of TNFAIP9 protein levels in adipose tissue between two groups. A. Western blot of TNFAIP9 protein in adipose tissue of two groups. B. Comparison of TNFAIP9 protein in adipose tissue of two groups. $* \mathrm{P}<0.05$.

\section{Relationship between physiological parameters in two groups}

Compared with the control group, the values for wc, body mass, BMI, fat, TC, TG, LDL-C, HOMA-IR, and ET significantly increased, and the level of HDL-C significantly decreased in obese children $(\mathrm{P}<0.05)$. The blood glucose levels were not statistically different between the two groups $(\mathrm{P}>0.05)$ (Tables 1 and 2).

Table 1. Comparison of obesity indexes in two groups.

\begin{tabular}{l|l|c|c|c|c}
\hline Groups & $\mathrm{N}$ & Waist circumference $(\mathrm{cm})$ & Body mass $(\mathrm{kg})$ & BMI $\left(\mathrm{kg} / \mathrm{m}^{2}\right)$ & Fat $(\%)$ \\
\hline Control & 17 & $71.14 \pm 4.98$ & $57.32 \pm 5.21$ & $22.11 \pm 4.10$ & $25.17 \pm 2.98$ \\
\hline Obese & 36 & $101.33 \pm 11.12^{*}$ & $89.44 \pm 10.32^{*}$ & $33.19 \pm 5.09^{*}$ & $38.33 \pm 5.01^{*}$ \\
\hline
\end{tabular}

BMI, body mass index; Fat $(\%)$, percentage of body fat; $* \mathrm{P}<0.05$.

Table 2. Comparison of blood lipid and blood glucose levels in the two groups.

\begin{tabular}{l|c|c|c|c|c|c|c|c}
\hline Groups & $\mathrm{N}$ & $\mathrm{TC}(\mathrm{mM})$ & $\mathrm{TG}(\mathrm{mM})$ & LDL-C $(\mathrm{mM})$ & HDL-C $(\mathrm{mM})$ & FPG $(\mathrm{mM})$ & HOMA-IR & ET $(\mathrm{ng} / \mathrm{L})$ \\
\hline Control group & 17 & $1.02 \pm 0.28$ & $3.71 \pm 0.65$ & $2.01 \pm 0.51$ & $1.71 \pm 0.32$ & $5.81 \pm 1.03$ & $2.12 \pm 0.81$ & $30.65 \pm 7.16$ \\
\hline Obese group & 36 & $1.40 \pm 0.37^{*}$ & $4.89 \pm 0.76^{*}$ & $2.81 \pm 0.69^{*}$ & $1.32 \pm 0.32^{*}$ & $5.98 \pm 2.98$ & $4.11 \pm 0.76^{*}$ & $49.33 \pm 9.46^{*}$ \\
\hline
\end{tabular}

TC, total cholesterol; TG, triglyceride; LDL-C, low density lipoprotein cholesterol; HDL-C, high density lipoprotein cholesterol; FPG, fasting plasma glucose; HOMA-IR, insulin resistance index; ET, endothelin. ${ }^{*} \mathrm{P}<0.05$.

Genetics and Molecular Research 15 (3): gmr.15037995 


\section{Relationship between TNFAIP9 level and blood lipid, blood glucose and obesity indexes}

The relevant data showed that the protein expression of TNFAIP9 positively correlated with wc, body mass, BMI, fat, TC, TG, LDL-C, HOMA-IR, and ET levels $(\mathrm{P}<0.05)$. TNFAIP9 protein level negatively correlated with HDL-C level $(\mathrm{P}<0.05)$.

\section{DISCUSSION}

Obesity is a global disease, which seriously affects human health due to metabolic disorders. At present, the mechanism of obesity is not entirely clear. Some hypotheses for the mechanism are energy surplus, insulin resistance, and uncoupling of proteins (Tang and Xie, 2008; Zhang et al., 2012), but it is not clear what the core mechanisms of obesity are at present. Recent research shows that the serum levels of inflammatory factors such as IL-6, TNF- $\alpha$, C-reactive protein, and haptoglobin in obese patients are significantly higher than those in the normal population. More evidence shows that chronic inflammatory state is one of the main causes of obesity (Engström et al., 2003; Park et al., 2010). TNF- $\alpha$ is the main inflammatory mediator, and the level of TNF- $\alpha$ is abnormally increased in the serum of asymptomatic obese patients, suggesting that TNF- $\alpha$ plays a vital role in the development of obesity (Mendoza-Azpur et al., 2015).

Researchers found that TNFAIP9 knockout mice spontaneously developed myotenositis and synovitis, resulting in a significant increase in IL-6 levels in peripheral blood, increase in the CD11 B cell content in the spleen, Thelper (Th) 1 cell activation, and significant enhancement of Th17 cell responses (Takai et al., 2015). This result showed that TNFAIP9 plays an important role in the inflammatory process. Recent studies have shown that there is a close relationship between TNFAIP9 protein and obesity (Matsumoto et al., 2014). This study showed that the levels of TNFAIP9 mRNA and protein were significantly decreased in obese children compared to normal children, and the TNFAIP9 protein is involved in the occurrence of obesity, where it plays a negative regulatory role. We further analyzed the relationship between TNFAIP9 protein and obesity, and the results showed that the wc, body weight, BMI, fat, TC, TG, LDL-C, HOMA-IR, and ET significantly increased in obese children compared to normal children. HDL-C levels decreased in obese children compared to normal children. The correlation analysis between TNFAIP9 protein level and the above indicators showed that the level of TNFAIP9 was negatively correlated with the wc, body mass, BMI, fat, TC, TG, LDL-C, HOMA-IR, and ET, but was positively correlated with HDL-C. This result further proved that TNFAIP9 is closely related to obesity, and low expression of TNFAIP9 protein might result in a significant increase in the inflammatory level, resulting in a variety of physiological changes in obesity.

In short, TNFAIP9 protein is involved in the occurrence of obesity and may provide a new therapeutic target for obesity. This could be a potential breakthrough in the treatment of obesity.

\section{Conflicts of interest}

The authors declare no conflict of interest.

Genetics and Molecular Research 15 (3): gmr.15037995 


\section{REFERENCES}

Ando M, Sato Y, Takata K, Nomoto J, et al. (2013). A20 (TNFAIP3) deletion in Epstein-Barr virus-associated lymphoproliferative disorders/lymphomas. PLoS One 8: e56741.http://dx.doi.org/10.1371/journal.pone.0056741

Bastard JP, Maachi M, Lagathu C, Kim MJ, et al. (2006). Recent advances in the relationship between obesity, inflammation, and insulin resistance. Eur. Cytokine Netw. 17: 4-12.

Chen LT (2009). Research progress of the obesity problem. Shandong Med. J. 49: 112-113.

Engström G, Hedblad B, Stavenow L, Lind P, et al. (2003). Inflammation-sensitive plasma proteins are associated with future weight gain. Diabetes 52: 2097-2101. http://dx.doi.org/10.2337/diabetes.52.8.2097

Esser N, Legrand-Poels S, Piette J, Scheen AJ, et al. (2014). Inflammation as a link between obesity, metabolic syndrome and type 2 diabetes. Diabetes Res. Clin. Pract. 105: 141-150.http://dx.doi.org/10.1016/j.diabres.2014.04.006

Fu Y, Lan J and Yu F (2014). Different obesity types and risk factors of chronic diseases in elderly people in Shanxi Province. Chin. J. Gerontol. 34: 3724-3727.

Inoue A, Matsumoto I, Tanaka Y, Umeda N, et al. (2012). Murine tumor necrosis factor a-induced adipose-related protein (tumor necrosis factor a-induced protein 9) deficiency leads to arthritis via interleukin-6 overproduction with enhanced NF-kB, STAT-3 signaling, and dysregulated apoptosis of macrophages. Arthritis Rheum. 64: 3877-3885. http://dx.doi.org/10.1002/art.34666

Ji CY, Sun JL and Chen TJ (2004). Dynamic analysis on the prevalence of obesity and overweight school-age children and adolescents in recent 15 years in China. Zhonghua Liu Xing Bing Xue Za Zhi 25: 103-108.

Johnston BC, Kanters S, Bandayrel K, Wu P, et al. (2014). Comparison of weight loss among named diet programs in overweight and obese adults: a meta-analysis. JAMA 312: 923-933. http://dx.doi.org/10.1001/jama.2014.10397

Liu M, Sun Z, Zhou A, Li H, et al. (2010). Functional characterization of the promoter region of human TNFAIP1 gene. Mol. Biol. Rep. 37: 1699-1705. http://dx.doi.org/10.1007/s11033-009-9588-1

Matsumoto I, Inoue A, Takai C, Umeda N, et al. (2014). Regulatory roles of tumor necrosis factor alpha-induced proteins (TNFAIPs) 3 and 9 in arthritis. Clin. Immunol. 153: 73-78. http://dx.doi.org/10.1016/j.clim.2014.03.015

Mendoza-Azpur G, Castro C, Peña L, Guerrero ME, et al. (2015). Adiponectin, leptin and TNF-a serum levels in obese and normal weight Peruvian adults with and without chronic periodontitis. J. Clin. Exp. Dent. 7: e380-e386. http:// dx.doi.org/10.4317/jced.52350

Park EJ, Lee JH, Yu GY, He G, et al. (2010). Dietary and genetic obesity promote liver inflammation and tumorigenesis by enhancing IL-6 and TNF expression. Cell 140: 197-208.http://dx.doi.org/10.1016/j.cell.2009.12.052

Schwingshackl L and Hoffmann G (2013). Comparison of effects of long-term low-fat vs high-fat diets on blood lipid levels in overweight or obese patients: a systematic review and meta-analysis. J. Acad. Nutr. Diet. 113: 1640-1661. http://dx.doi.org/10.1016/j.jand.2013.07.010

Takai C, Matsumoto I, Inoue A, Umeda N, et al. (2015). Specific overexpression of tumour necrosis factor-a-induced protein (TNFAIP) 9 in CD14(+) CD16(-) monocytes in patients with rheumatoid arthritis: comparative analysis with TNFAIP3. Clin. Exp. Immunol. 180: 458-466. http://dx.doi.org/10.1111/cei.12606

Tang $\mathrm{H}$ and Xie MH (2008). Research progress of obesity and exercise: chronic inflammatory reaction theory. Sports Science 28: 54-58.

Zhang C, Kallakury BV, Ross JS, Mewani RR, et al. (2013). The significance of TNFAIP8 in prostate cancer response to radiation and docetaxel and disease recurrence. Int. J. Cancer 133: 31-42.http://dx.doi.org/10.1002/ijc.27996

Zhang JF, Yao GY and Wu YH (2012). Expression profiling based on coexpressed modules in obese prepubertal children. Genet. Mol. Res. 11: 3077-3085.http://dx.doi.org/10.4238/2012.August.31.5

Genetics and Molecular Research 15 (3): gmr.15037995 